doi: $10.2306 /$ scienceasia1513-1874.2014.40.436

\title{
Detection of hidden faults beneath Khlong Marui fault zone using seismic reflection and 2-D electrical imaging
}

\author{
Kasemsak Saetang ${ }^{\mathrm{a}, \mathrm{b}}$, Sawasdee Yordkayhun ${ }^{\mathrm{a}, \mathrm{c}, *}$, Kamhaeng Wattanasen ${ }^{\mathrm{a}, \mathrm{c}}$ \\ a Department of Physics, Faculty of Science, Prince of Songkla University, Hat Yai, Songkhla 90112 Thailand \\ b Department of Physics, Faculty of Science and Technology, Nakhon Si Thammarat Rajabhat University, \\ Mueng, Nakhon Si Thammarat 80280 Thailand \\ c Geophysics Research Centre, Prince of Songkla University, Hat Yai, Songkhla 90112 Thailand
}

${ }^{*}$ Corresponding author, e-mail: sawasdee.y@psu.ac.th

Received 10 Jun 2014

Accepted 26 Nov 2014

\begin{abstract}
The Khlong Marui fault zone is a major fault located in the southern part of Thailand extending across the peninsula. In spite of the available information on fault segments and tectonic activity associated with faulting, the local scale fault characteristics are currently barely known and are often difficult to detect in areas where surface displacement has not occurred. The present geological field investigation reveals that the study area in Surat Thani province possibly contains more minor faults where the shallow faulting is evident. To detect fault locations and to study fault characteristics, seismic reflection analysis and 2-D electrical imaging were applied along the three survey lines as a case study. After data processing, an interpretation was proposed based on the correlation of geophysical results with the geological information. Discontinuities in the main horizons in seismic sections and correlatable zones in resistivity imaging indicate that faulting is present in a Permian-Carboniferous unit and may extend to the shallow subsurface in Quaternary sediments.
\end{abstract}

KEYWORDS: tectonic plate, transtension, electrical resistivity

\section{INTRODUCTION}

In 2004, more than 286000 people in the Indian Ocean border, including Thailand, Indonesia, Sri Lanka, and India were killed as a consequence of the great tsunami associated with a large earthquake (Mw of 9.1) occurring off the west coast of Northern Sumatra $^{1}$. After this natural disaster, numerous studies about earthquake hazards and their mechanisms have been undertaken.

Records of destructive earthquakes in Thailand and surrounding areas are mainly the results of epicentres in the Sumatra-Andaman subduction zone and in some active faults in the western and northern parts of Thailand ${ }^{2}$. Hence accurate fault location and characterization are important to understand the tectonic and seismic hazard dynamics.

Recently, the Department of mineral resources (DMR) reported that there are 15 active fault zones within the country ${ }^{3}$. Among them, Ranong fault zone (RFZ) and Khlong Marui fault zone (KMFZ) are the two NNE-SSW striking active fault zones located in the southern region of Thailand ${ }^{4}$. Although the two faults are capable of producing small earthquakes ${ }^{5,6}$, evidence from an earthquake of magnitude 4.3 hit on Phuket province in 2012 as well as the currently developed seismic hazard map for southern Thailand shows a high ground shaking along the fault zones where the maximum ground motion is located along the $\mathrm{KMFZ}^{7}$. This study therefore focuses on the KMFZ that cut across the Thai peninsula from the western part of Phuket province towards Surat Thani province.

A number of studies using both invasive and non-invasive techniques have been conducted in the KMFZ area to clarify that southern Thailand is not tectonically stable as had previously been thought. For example, Electron Spin Resonance technique was able to date the occurrence of Mw 6.5 palaeo-earthquakes at about 2000 and 3000 years ago at Bang Leuk palaeoseismic trench ${ }^{8}$. Active fault segments at Khao Phanom area were revealed by applying mountain front sinuosity index and stream length gradient index techniques ${ }^{9}$. A report of active fault study using instrumental and historical earthquake data, remote sensing interpretation, trenching, and topographic surveys conducted by $\mathrm{DMR}^{10}$ reveal a number of major fault segments with orientations along the RNF and KMFZ. For geophysical studies, horst and graben structures were identified at a geothermal area in Chaiya district and Tha Chang district using gravity method $^{11}$. In addition, KMFZ and related fault zones 


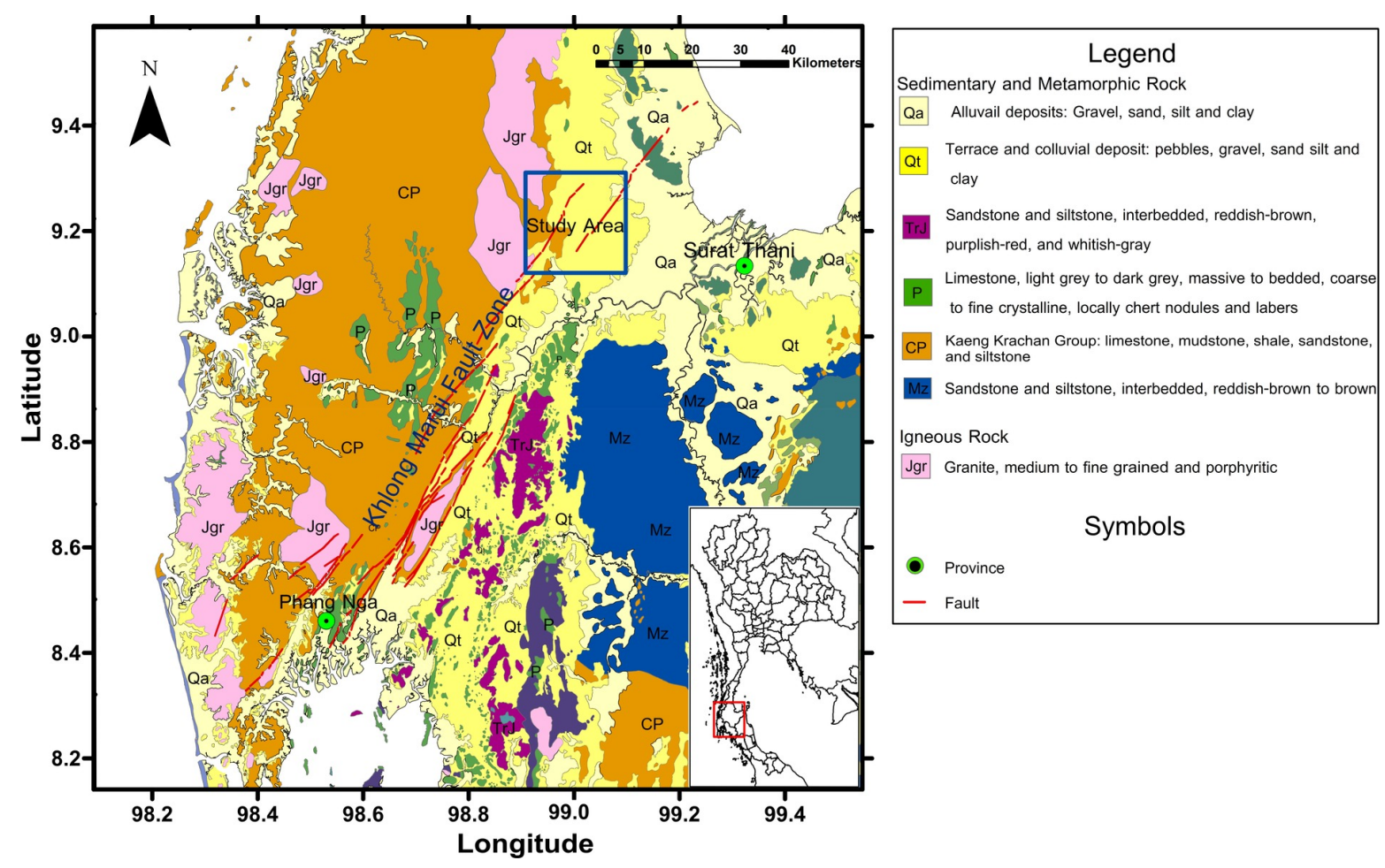

Fig. 1 Geological map showing the KMFZ and the study area.

were used as a case study for earthquake warnings using radon monitors ${ }^{12}$.

In 2011, an integrated geophysical study of the fault zone project was started. As a part of this project, Vibhavadee district, Surat Thani province was selected as a case study because local geological surveys and outcrop data suggested possible faulting near the surface ${ }^{13}$ and geophysical methods have not been performed earlier. The area lies within the proposed KMFZ segments (Fig. 1) where faults cannot be inferred by examining geological maps ${ }^{10,14}$. Note that the construction of the fault segments in Fig. 1 is based on interpretation of remote sensing data, trenching, topographic, and radon surveys ${ }^{10}$. Hence the purposes of this study are to detect minor fault locations and to understand its characteristics using geophysical methods. It is known that geophysical techniques are effective tools used in numerous fault investigations ${ }^{15-18}$. This study utilized the seismic and resistivity methods in an attempt to establish a link between shallow and deeper faults and the associated tectonic in the area.

\section{Tectonic and geological setting}

The tectonic settings of Thailand and surrounding areas have been controlled by interactions of IndoAustralian, Eurasian, Phillippine, and West Pacific plates in combination with Andaman sea opening ${ }^{2,19-21}$. This causes a transtension in Thailand with extension along the north-south faults, right-lateral slip on the northwest-striking faults, and left-lateral slip on the northeast-striking faults ${ }^{22-25}$. For southern Thailand, RFZ and KMFZ are major strike-slip fault extending from southwest to northeast that appear to intersect in the northern Gulf of Thailand. KMFZ runs through Phuket, Thap Put district in Phang Nga province, Phanom and Viphavadi district in Surat Thani province, under an area of about $150 \mathrm{~km}$ long and $10 \mathrm{~km}$ wide $^{2,7,10}$. The DMR report together with cooperative research studies by Chulalongkorn University, Thailand reveal that KMFZ consists of 10 fault segments ${ }^{10}$. In the study area, Ban Kiam Phoe fault segment and Vibhavadee fault segments (Fig. 2) are inferred from the main morphotectonic features and trenching, showing evidence of movement during the Quaternary period.

The geological information based on the DMT report ${ }^{10,14}$ is shown in Fig. 1. The study area comprises sedimentary rocks of Palaeozoic to Cenozoic ages. The oldest rocks are Permian-Carboniferous, composed of limestone, mudstone, shale, sandstone, and silt stone. This rock crops out in the western hills. The limestone is grey to dark grey colour and usually appear in thick to massive beds. In 


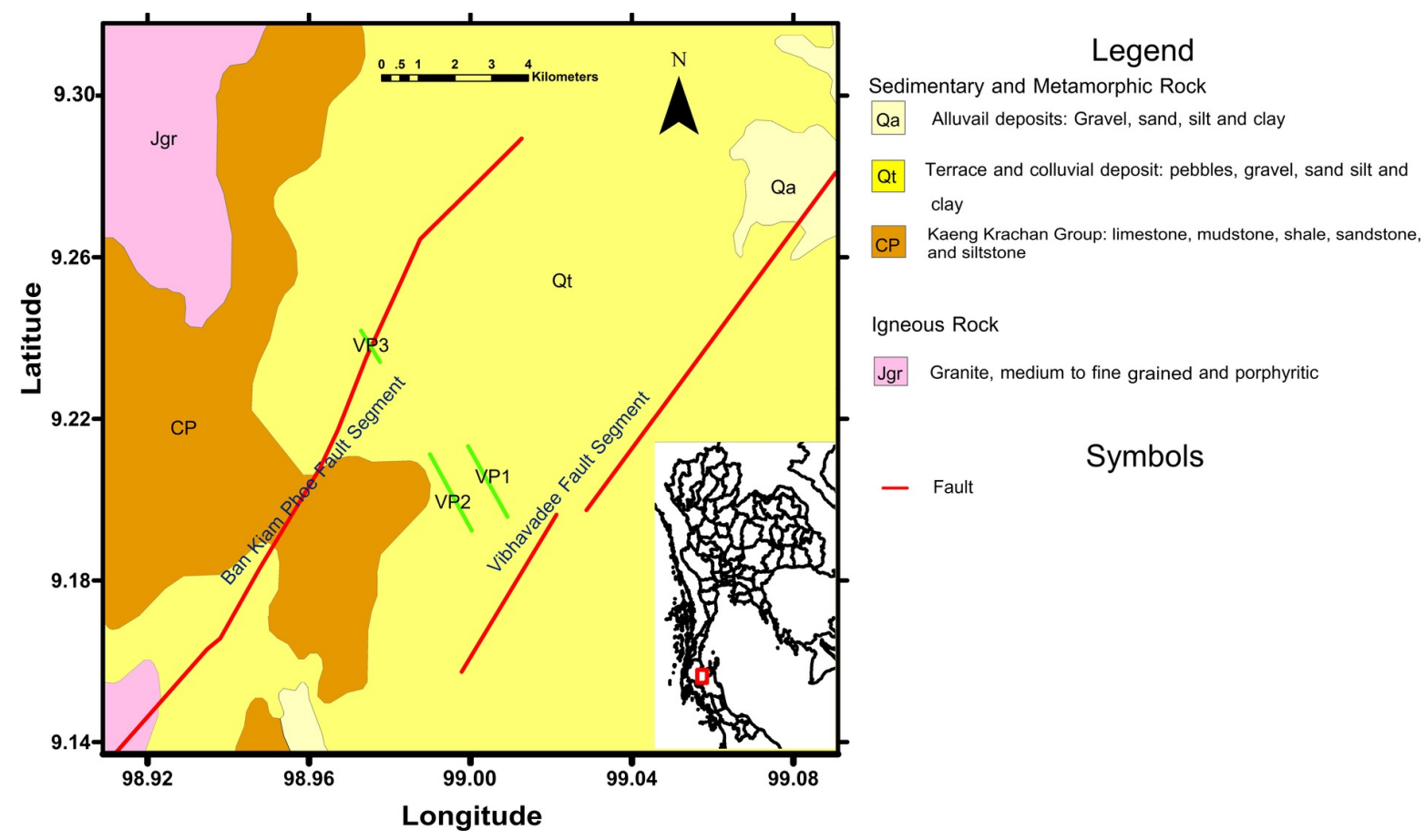

Fig. 2 Location map showing three survey lines (VP1, VP2, and VP3 marked as the green lines) which run perpendicular to the faults.

some areas, limestone was transformed to dolomite. Locally, a report of geological field investigation in the Vibhavadee area conducting by Prince of Songkla University (PSU) ${ }^{13}$ revealed evidence of faults in Permian-Carboniferous sandstone outcrop which appear to be complex with two major populations, NWSE and NNE-SSW orientations.

Permian limestone occurs in the middle part which contains of Permian fossils. The yellow-brown siltstones found were thinly bedded and contained carbonaceous layers. Triassic-Jurassic granite rocks consisted of batholiths and plutonic rocks. TriassicJurassic sedimentary rocks of Mesozoic age are distributed in the eastern part, composed of sandstone, siltstone, limestone lenses, and conglomerate. These sandstones are maroon to brownish-red and the grain size is medium to coarse. The yellowish-brown siltstone contains carbonaceous layers. Limestone lenses have bivalves and foraminifers inside. The conglomerate contains limestone pebbles in a red sand matrix. Quaternary sediments consist of terrace deposits and fluvial deposits, covering a large area in western and eastern part. The terrace deposit consists of clay, sand, and gravel layers. The sand layers are very coarse grain size which is poorly sorted. The fluvial deposit composes of silty clay layers which alternate with sand layers. The sequences are found along the main rivers and shorelines.

\section{METHODS}

Reflection seismic and 2-D electrical imaging are the geophysical methods used for this study. Reflection seismic attempts to detect possible change in elastic properties and/or density within the subsurface by recording and analysing the reflected wave generated by seismic boundaries, after the elastic waves have propagated from the sources. It is generally a noninvasive tool for groundwater exploration, site investigation, fault detections and petroleum prospecting ${ }^{15-17,26}$. Electrical imaging is based on indirect measurements of the electrical properties of subsurface by injecting the current into the ground and measuring the voltage difference through a set of electrode configuration. The apparent resistivity is calculated based on the relationship between current and voltage that is governed by Ohm's law. The electrical resistivity distribution as a 2-D cross-section is obtained by performing data inversion ${ }^{27,28}$. It is effective method in groundwater and environmental studies ${ }^{29,30}$. In this study, seismic and resistivity sections will be correlated with available geology information for the interpretation. Data acquisition and processing of these techniques are briefly described below. 
Table 1 Processing steps.

\begin{tabular}{|c|c|c|}
\hline Step & & Descriptions and parameters \\
\hline 1. & Setup of field geometry & Assign input shot locations and receiver locations into headers \\
\hline 2. & Editing bad traces & Remove bad traces \\
\hline 3. & Elevation statics and refraction statics & Calculate static corrections based on near surface models and elevations \\
\hline 4. & Band-pass filtering & $\begin{array}{l}\text { Minimum phase Butterworth filtering } \mathrm{f}_{\mathrm{c}}=20,40,100,200 \mathrm{~Hz} \text {, } \\
\text { Design Amplitude }=0,1,1,0\end{array}$ \\
\hline 5. & Automatic gain control (AGC) & Adjust reflection amplitude using $100 \mathrm{~ms}$ window \\
\hline 6. & Bottom mute & Zero data in the ground roll range \\
\hline 7. & CMP sorting & Sort data by common midpoint number \\
\hline 8. & Velocity analysis & Find velocity values that fit layers \\
\hline 9. & NMO correction & Apply stacking velocity function including $70 \%$ stretch mute \\
\hline 10. & Stack & \\
\hline 11. & Relative trace balancing & $0-512 \mathrm{~ms}$ range \\
\hline
\end{tabular}

\section{Data acquisitions}

Geophysical investigations were conducted along 3 survey lines in June 2011. The survey lines, namely VP1, VP2, and VP3, were oriented northwest to southeast and were roughly perpendicular to the strike of KMFZ segments (Ban Kiam Phoe Fault segment and Vibhavadee Fault segment ${ }^{10}$ ) (Fig. 2). The total lengths of the survey lines are $2100 \mathrm{~m}, 2200 \mathrm{~m}$ and $900 \mathrm{~m}$, respectively. VP1 and VP2 laid between the two fault segments in order to detect minor faults, whereas VP3 was performed across a fault segment to verify the fault location. The survey lines are on agricultural roads where the traffic was quiet, simplifying the data acquisition. However, surface relief along the VP1 and VP2 survey lines are somewhat modulate.

For seismic reflection, common midpoint geometry (CMP) was applied for data acquisition. Twelve vertical geophones $(14 \mathrm{~Hz}$ single) were deployed into the ground and connected with roll along system. Receiver and source spacing of $5 \mathrm{~m}$ were set to create stacked sections with $2.5 \mathrm{~m}$ between CMP traces. The maximum 6 folds CMP coverage along survey lines was obtained. A $10 \mathrm{~kg}$ sledge hammer was selected for an active source and 10-15 repeated shots were stacked to enhance the signal-to-noise ratio. However, a few shot points were skipped due to the present of river and bridge on the survey lines. The start recording time was controlled by a hammer trigger sensor installed on the hammer and transmitted the trigger pulses to the recording system by cable links. Walk-away noise tests before collecting data suggest that $30 \mathrm{~m}$ near offset appeared to be the optimum window. The data were recorded by a 24 channel Geometric SmartSeis recording system. Record length and sampling interval were set up to $512 \mathrm{~ms}$ and $0.25 \mathrm{~ms}$, respectively.

For 2-D electrical imaging, data were acquired using Dipole-Dipole configuration a good resolution of horizontal layer and sensitive to depth ${ }^{27}$. An ABEM Terrameter SAS 1000 was used as the re- sistivity meter. Three to six repeated measurements were recorded for each point in order to constrain a standard deviation of less than 3\% for the apparent resistivity value. Stainless steel electrode of $8 \mathrm{~m}$ spacing, rolled along in survey line with the range of $n=1-6$ created resistivity sections corresponding to roughly $4 \mathrm{~m}$ down to $20 \mathrm{~m}$ depth.

\section{Data processing}

The main goals of geophysical data processing are to construct high quality images of subsurface and make it suitable for the structural interpretation.

For reflection seismic data were processed using Globe ClaRITAS Version 5.5 software developed by geological \& Nuclear (GNS Science), New Zealand ${ }^{31}$. Processing sequences to improve data quality were based on standard techniques (Table 1). Geometry assignment and editing bad traces were done as initial step. First arrival time picking and near surface modelling were used for static corrections (elevation statics and refraction statics). The static corrections removed a 5-10 m thick of covered layer which has velocity of $900 \mathrm{~m} / \mathrm{s}$. A selected shot gather shown in Fig. 3a indicates that ground roll is consistent in the raw data. Hence $40-100 \mathrm{~Hz}$ band pass filter was designed to suppress influences of low and high frequency noises based on the spectrum analysis. Automatic gain control of traces was done for visualization using $100 \mathrm{~ms}$ time widows (Fig. 3b). Although frequency filter has potential to reduce low frequency noise, a bottom mute was applied for the ground roll removal (Fig. 3c). After sorting the shot gathers into CMP gathers, velocity analysis was performed iteratively based on constant velocity stack and semblance to determine stacking velocity functions. Normal moveout (NMO) correction was used with 70\% stretch mute to reduce unwanted first arrival stacking. Stacking was done to increase the signal-to-noise ratio and relative trace balancing was applied for better display of the stacked sections. 


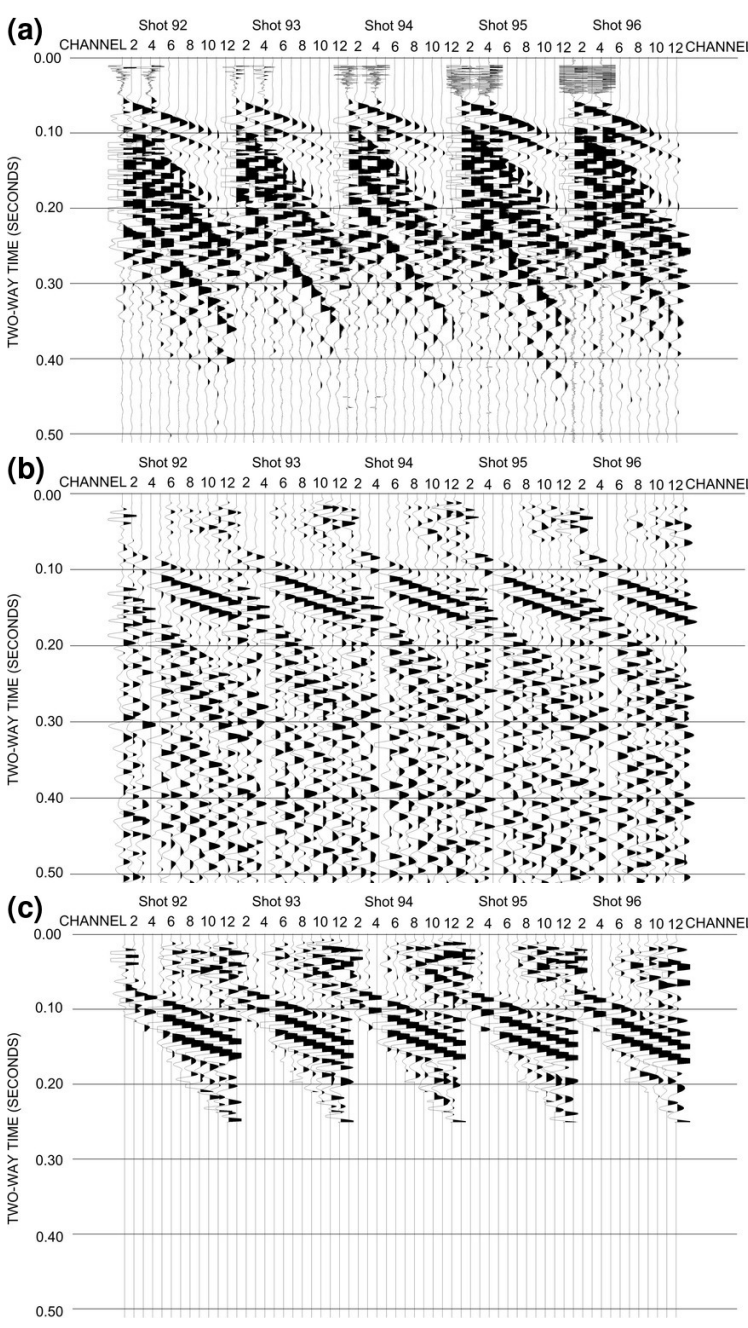

Fig. 3 A selected shot gather showing (a) raw data, (b) the results after some processing steps were applied, including editing, static corrections, filtering and AGC. (c) A bottom mute was applied in a range for removal of the ground roll.

For 2-D electrical imaging, models of resistivity pseudosections were created using RES2DINV Version 3 software developed by Geotomo Software ${ }^{32}$. The software utilized iterative inversion method to convert the measured apparent resistivity with different electrode configurations into 2-D true resistivity sections. A nonlinear least square optimization technique $^{33,34}$ was applied for adjusting models to fit the measured data. Due to the non-uniqueness of solutions commonly encountered in the inversion process, inversion parameters and a priori information need to be tested. Removal of poor data and topography corrections appeared to improve data quality. The model resolution was decided by setting thickness of layer blocks. The thickness of first layer blocks was set from 0.9 time of the electrode spacing, whereas the thickness of subsequent deeper layers was set to increase by $10 \%$. The software tried to get best fitting by adjusting resistivity model blocks with minimize root mean square (RMS) error. After 4-6 iterations, calculated models with RMS error lower than 5\% were obtained. The optimum models were selected based on tracking the RMS errors and considering geological information. For comparison purpose in this study, the final resistivity models were plotted using Surfer V7 software ${ }^{35}$.

\section{RESULTS AND DISCUSSION}

To identify sedimentary units and fault characteristics, seismic time sections were converted to depth sections and overlain by resistivity sections (Fig. 4). Due to a poorly controlled seismic line, the depth conversion was based on interval velocities that were inferred from stacking velocity field. Seismic data represent coherent subsurface structures from 30-150 m depth and is characterized by a seismic velocity increase with depth in the range of 1100-1600 m/s. Given the dominant frequencies of the data ranges from 40$60 \mathrm{~Hz}$, vertical resolution based on Rayleigh criteria is about $8-10 \mathrm{~m}$. Potential indicators of faulting in the seismic data are based on Sheriff ${ }^{36}$ including sharp reflector termination, presence of diffraction events, correlations of reflectors across fault plane, and coherency loss beneath a fault plane. In this study, numerous anomalous areas observed in the seismic sections may correspond to the faulting. The resistivity sections were interpreted to correlate the seismic reflection with the shallow subsurface structures. The lateral resistivity changes are potentially indicative of zones of faulting, but it is necessary to compare them with seismic data. The detailed interpretations of each survey line are described below.

Fig. 4a and Fig. 4b display uninterpreted and interpreted stacked sections of VP1 survey line. There appears to be evidence of fault at approximately $650 \mathrm{~m}, 850 \mathrm{~m}, 1250 \mathrm{~m}$, and $1600 \mathrm{~m}$ as marked by dot lines in Fig. 4b. The proposed faults are characterized by dips of greater than $45^{\circ}$. At $1600 \mathrm{~m}$, the dip is about $55^{\circ}$, whereas the rest are steeper and are generally at $60-80^{\circ}$. For VP2 survey line where run parallel with VP1 survey line, there is evidence of potential faults at $750 \mathrm{~m}, 1050 \mathrm{~m}, 1250 \mathrm{~m}, 1550 \mathrm{~m}$, and $2050 \mathrm{~m}$ (Fig. 4d). The dip angles of the possible faults are about $60^{\circ}-85^{\circ}$. It should be noted that most faults appear to have a small vertical offset. This observation agrees with the main structural feature in the outcrop which indicates an extensional rather than compressional character of the fault due to the mass 

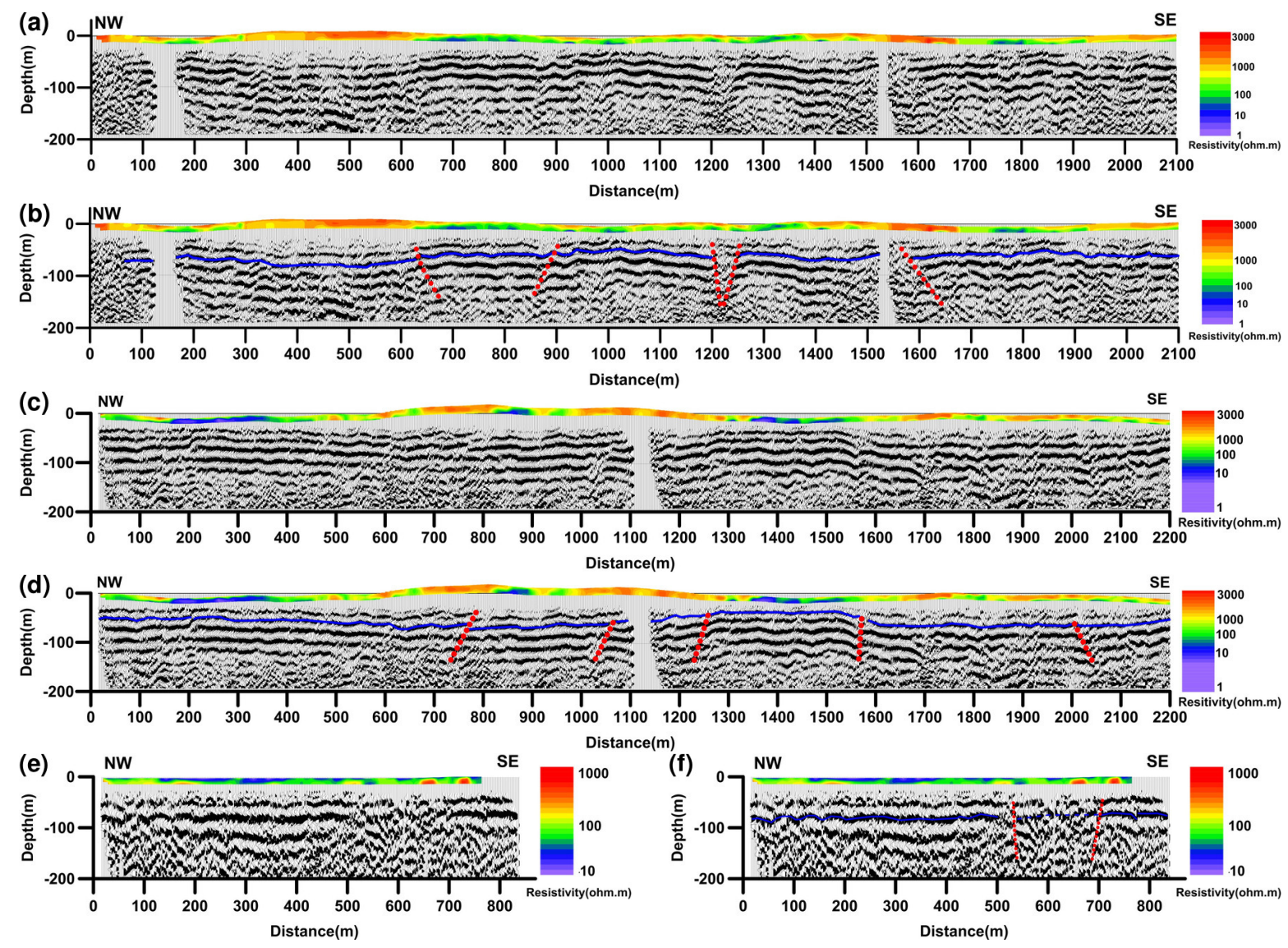

Fig. 4 (a) Seismic section overlain by the resistivity section of VP1. (b) Same as (a) after interpretations. Possible fault locations are marked as red dot lines. The coherent reflector highlighted as blue lines is assumed to be the transition zone between the Quaternary and Permian-Carboniferous units. (c) Seismic section overlain by the resistivity section of VP2. (d) Same as (c) after interpretations. (e) Seismic section overlain by the resistivity section of VP3. (f) Same as (e) after interpretations, illustrating the fault confirmation of Ban Kiam Phoe fault segment.

balance, as can be inferred from almost undisturbed bended structure of the gravel layer below top soil ${ }^{12}$. Moreover, it is consistent with a set of offset stream that indicates the lateral shear sense. Although a number of horizons can be observed in the seismic section, a key horizon was marked for the structural interpretation due to poor control. The first coherent reflector in seismic sections is mostly seen at approximately 50-60 m depth (marked as a blue solid line in Fig. 4b). On the basis of geological information, topography, and outcrop data, a thin Quaternary sediments cover is expected in the study area. This horizon is therefore interpreted to be a base of Quaternary sediments or transition zone between Quaternary and Permian-Carboniferous unit. The inherent amplitude of this horizon as observed in the raw data in Fig. 3 probably indicates a sharp contrast of elastic properties between the two units. The deeper horizons may correspond to the sedimentary sequences of a Permian-Carboniferous unit. This feature is consistent with those highlighted in VP2 (Fig. 4d) and VP3 (Fig. 4f) survey lines. Visual inspection of the seismic data suggests that the Permian-Carboniferous unit is highly fractured in the survey lines as can be inferred from the signal attenuation at greater depths.

For resistivity results, it is possible to distinguish the saturated and unsaturated zones based on tracking a resistivity value of $100 \Omega \mathrm{m}$ in resistivity sections. Relative low resistivity zones $(<100 \Omega$ m) may indicate saturated zones or sediments with high clay content which are often observed adjacent to channel and swamp areas. Higher resistivity zones are thought to represent unsaturated zones of unconsolidated sediments. As previously mentioned, although rapid changes in resistivity may suggest the presence of fault at the near surface, it is insufficient to make a 
reasonable judgement because anomalous zones may be caused by factor such as changes in geohydrologic conditions, lithology, or presence of channel cut and fill ${ }^{37-40}$. For VP1 and VP2 survey lines, resistivity values may be suspected to associate with terrain because low resistivity zones are found on both sides of the hill.

For VP3 survey line, the result shows that Ban Kiam Phoe fault segment has been mapped at 550$700 \mathrm{~m}$ with dip angle of about $85^{\circ}$ (Fig. 4f). Although the deformation zone is further east of the proposed fault segment, it indicates the existence of a fault trace. The lack of visible offset in the seismic section at the deformation fault zone may indicate strike-slip faults deformation with small transtension. The low resistivity areas $(<50 \Omega \mathrm{m})$ near the ground surface seen in Fig. $4 \mathrm{f}$ can be interpreted as a zone of saturated sediment or high clay content. This is supported by geological data and the presence of a canal in the middle part of the line. No clear evidence of discontinuity indicates faults in the resistivity data, suggesting that the fault may not extend far enough into the near surface.

\section{Conclusions}

Seismic reflection and resistivity data obtained across the KMFZ confirm the existing of a proposed fault segment and detect a number of hidden faults beneath the KMFZ fault zones. Overall, the new finding faults through the Permian-Carboniferous unit are likely to have steep dip with small offset of throw, characterising the strike-slip faults deform with small transtension. The study area is overlain by Quaternary sediments, extending approximately $50 \mathrm{~m}$ into the subsurface before transitioning to a sequence of Permian-Carboniferous unit. Resistivity data provide insufficient resolution for determining a shallow fault, but combined with seismic data it can constrain the interpretation to suggest that faulting may extend to the near surface. This is also supported by geologic surveys showing shallow fault outcrops visible in the area. Although geophysical data confirm the location of the fault and related shallow faulting, some fundamental problems remain poorly understood, such as deeper structures, fault length and strike, and verification of active fault. Consequently, a larger scale investigation and dating in a trench should be performed in the future.

Acknowledgements: The authors would like to thank Graduate School Faculty, Prince of Songkla University (PSU) and Electricity Generating Authority of Thailand for financial support. Geophysics Research Centre, PSU, is thanked for the software supporting. Equipment was provided by the International Program in Physical Science, Uppsala University, Sweden. Helmut Dürrast is thanked for providing geological data. Graduate and undergraduate physics students, PSU, are thanked for their assistance with field work. We are grateful for constructive comments of anonymous reviewers that enhanced the quality of the paper.

\section{REFERENCES}

1. Geist EL, Titov VV, Arcas D, Pollitz FF, Bilek SL (2007) Implications of the 26 December 2004 SumatraAndaman earthquake on tsunami forecast and assessment models for great subduction-zone earthquakes. Bull Seismol Soc Am 97, S249-70.

2. Charusiri P, Daorerk V, Archibald D, Hisada K, Ampaiwan T (2002) Geotectonic evolution of Thailand: A new synthesis. J Geol Soc Thai 1, 1-20.

3. Department of Mineral Resources (2014) Active fault zones in Thailand. www.dmr.go.th/main.php? filename $=$ fault_En. Ministry of Natural Resources and Environment, Thailand.

4. Watkinson I, Elders C, Hall R (2008) The kinematic history of the Khlong Marui and Ranong Faults, southern Thailand. J Struct Geol 30, 1554-71.

5. Dangmuan S (2008) Seismic study of Southern Thailand after the 26 December 2007 Sumatra Andaman earthquake. MSc thesis, Prince of Songkla Univ, Thailand.

6. Duerrast H, Dangmuan S, Lohawijarn W (2007) Khlong Marui and Ranong fault zones in southern Thailand re-activated by the 26 December $2004 \mathrm{Mw} 9.3$ Sumatra-Andaman earthquake. In: Proceedings of the 2007 International Conference on Geology of Thailand: Towards Sustainable Development and Suffciency Economy, GEOTHAI'07, Bangkok, pp 141-4.

7. Sutiwanich C, Hanpattanapanich T, Pailoplee S, Charusiri P (2012) Probability seismic hazard maps of Southern Thailand. Songklanakarin J Sci Tech 34, 453-66.

8. Chansawad P, Dowrerk V, Kosuwan S, Pailoplee S, Charusiri P (2008) Application of ESR-dating results and remote-sensing to constrain active tectonics along the southern part of Khlong Marui Fault, Southern Thailand. In: Proceedings of the International Symposia on Geoscience Resources and Environments of Asian Terranes (GREAT 2008), Bangkok, pp 122-5.

9. Kaewmuangmoon S, Thipyopass S, Kosuwan S, Daorerk V, Charusiri P (2008) Investigations on tectonic geomorphology along the Khlong Marui Fault, Kao Phanom area, Southern Thailand: Application of ArcGIS Approach. In: Proceedings of the International Symposia on Geoscience Resources and Environments of Asian Terranes (GREAT 2008), Bangkok, pp 126-9.

10. Department of Mineral Resources (2007) Investigation on recurrence interval of faults in Prachub Khirikhun, Chumporn, Ranong, Surat Thani, Krabi, Phangnga and 
Phuket provinces (Ranong and Khlong Marui faults) carried out by the Department of Geology, Faculty of Science, Chulalongkorn Univ (in Thai).

11. Khawtawan A (2007) Geophysical study of geothermal resources in Surat Thani Province. MSc thesis, Prince of Songkla Univ, Thailand.

12. Pisapak P, Dürrast H, Bhongsuwan T (2010) Soil-Gas Radon as a Possible Earthquake Precursor: A Case Study from the Khlong Marui Fault Zone, Southern Thailand. Kasetsart J (Nat Sci) 44, 1079-93.

13. EGAT (2013) Integrated geophysical studies of the fault zones in southern Thailand carried out by the Geophysics Research Center, Prince of Songkla Univ (in Thai).

14. Department of Mineral Resources (1985) Digital Geological Map of Thailand 1:250000, Ministry of Natural Resources and Environment, Thailand.

15. Kuria ZN, Woldai T, van der Meer FD, Barongo JO (2010) Active fault segments as potential earthquake sources: Inferences from integrated geophysical mapping of the Magadi fault system, southern Kenya Rift. J Afr Earth Sci 57, 345-59.

16. Pratt TL, Dolan JF, Odum JK, Stephenson WJ, Williams RA, Templeton ME (1998) Multiscale seismic imaging of active fault zones for hazard assessment: A case study of the Santa Monica fault zone, Los Angeles, California. Geophysics 63, 479-89.

17. Odum KJ, Stephenson WJ, Williams RA, Worley DM, Guccione MJ, Arsdale RBV (2001) High resolution seismic-reflection imaging of shallow deformation beneath the northeast margin of the Manila high at Big Lake, Arkansas. Eng Geol 62, 91-103.

18. Fuji-ta K, Ikuta O (2000) Resistivity structure of the central part of the Yamasaki fault studied by the multiple electrodes resistivity method. Earth Planets Space 52, 567-71.

19. Metcalfe I (2009) Late Paleozoic and Mesozoic tectonic and paleogeographical evolution of SE Asia. Geol Soc Lond Spec Publ 315, 7-23.

20. Bunopas S, Vella P (1983) Tectonic and geologic evolution of Thailand. In: Proceeding of the Workshop on Stratigraphic Correlation of Thailand and Malaysia, Hat Yai, Thailand, pp 307-23.

21. Morley CK (2004) Nested strike-slip duplexes, and other evidence for Late Cretaceous-Paleogene transpressional tectonics before and during India-Eurasia collision, in Thailand, Myanmar and Malaysia. J Geol Soc 161, 799-812.

22. Pigott JD, Sattayarak N (1993) Aspects of sedimentary basin evolution assessed through tectonic subsidence analysis. Example: northern Gulf of Thailand. J Southeast Asian Earth Sci 8, 407-20.

23. Polachan S (1988) The geological evolution of the Mergui Basin, S.E. Andaman Sea. PhD thesis, Royal Holloway and Bedford New College, Univ of London.

24. Kornsawan A, Morley CK (2002) The origin and evolution of complex transfer zones (graben shifts) in conjugate fault systems around the Funan Field, Pattani Basin, Gulf of Thailand. J Struct Geol 24, 435-49.

25. Garson MS, Mitchell AHG (1970) Transform faulting in the Thai Peninsula. Nature 22, 45-7.

26. Sheriff RE, Geldart LP (1995) Exploration Seismology, 2nd edn, Cambridge Univ Press, Cambridge.

27. Loke MH (2012) Tutorial: 2-D and 3-D Electrical Imaging Surveys, Geotomo Software, Malaysia.

28. Loke MH (2011) Electrical resistivity surveys and data interpretation. In: Gupta HK (ed) Encyclopedia of Solid Earth Geophysics, 2nd edn, Springer, Dordrecht, pp 276-83.

29. Loke MH, Chambers JE, Kuras O (2011) Instrumentation, electrical resistivity. In: Gupta HK (ed) Encyclopedia of Solid Earth Geophysics, 2nd edn, Springer, Dordrecht, pp 599-604.

30. Loke MH, Dahlin T, Leroux V (2011) Constrained time-lapse inversion of 3-D resistivity surveys data. In: 17th European Meeting of Environmental and Engineering Geophysics, Leicester, United Kingdom.

31. Ravens J (2007) Globe Claritas, Seismic Processing Software Manual, Part 1, 5th edn, GNS Science, New Zealand.

32. Loke MH (2011) Rapid 2D Resistivity and IP Inversion Using the Least-Squares Method, Geotomo Software, Malaysia.

33. de Groot-Hedlin CD, Constable SC (1990) Occam's inversion to generate smooth, two-dimensional models from magnetotelluric data. Geophysics 55, 1613-24.

34. Sasaki Y (1992) Resolution of resistivity tomography inferred from numerical simulation. Geophys Prospect 40, 453-64.

35. Golden Software Inc (1999) Surfer User's Guide, Golden, Colorado, United States.

36. Sheriff RE (1982) Encyclopedic Dictionary of Exploration Geophysics, Society of Exploration Geophysicists, Tulsa, Oklahoma, United States.

37. Fazzito SY, Rapalini AE, Cortés JM, Terrizzano CM (2009) Characterization of Quaternary faults by electric resistivity tomography in the Andean Precordillera of Western Argentina. J S Am Earth Sci 28, 217-28.

38. Sandberg SK, Slater LD, Versteeg R (2002) An integrated geophysical investigation of the hydrogeology of an anisotropic unconfined aquifer. J Hydrol 267, 227-43.

39. Rucker DF, Noonan GE, Greenwood WJ (2011) Electrical resistivity in support of geological mapping along the Panama Canal. Eng Geol 117, 121-33.

40. Kagiyama T, Utada H, Yamamoto T (1999) Magma ascent beneath Unzen Volcano, SW Japan, deduced from the electrical resistivity structure. J Volcanol Geoth Res 89, 35-42. 